\title{
Gênese do discurso do planejamento urbano em Curitiba: bases políticas, filosóficas e técnicas
}

\author{
LEITÃO, Sylvia Ramos
}

\begin{abstract}
Resumo
O objeto desta pesquisa é o discurso do planejamento urbano em Curitiba. A metodologia adotada foi a da análise de conteúdo. Para identificar as bases que geraram o discurso, construiu-se um referencial histórico que contemplou a fase de institucionalização do processo do planejamento urbano na década de sessenta, e os marcos antecedentes que a influenciaram. Verificou-se a estreita vinculação entre a construção da identidade da cidade de Curitiba e o planejamento urbano - pensamento e ação do Estado sobre o espaço urbano. Identificaram-se a influência das abordagens humanista e racionalista do planejamento urbano sobre as bases geradoras do discurso, bem como a influência do contexto político, econômico e social em que tal discurso se inseriu. $O$ discurso do planejamento urbano, ao encerrar em si um projeto político, tem como produto a "imagem síntese" da cidade. Assim, pretende-se neste artigo discorrer sobre a gênese do discurso do planejamento urbano em Curitiba, identificando suas origens e distinguindo suas bases de sustentação. Para sua identificação, construiu-se um referencial histórico que contemplou a fase de institucionalização do processo do planejamento urbano em Curitiba na década de sessenta, bem como os marcos antecedentes que a influenciaram.
\end{abstract}

Palavras-chave: Discurso de Planejamento Urbano. Influências Humanista e Racionalista no Planejamento Urbano. Processo de Planejamento Urbano. Curitiba.

\begin{abstract}
:
The object of this research is the urban planning discourse conveyed in Curitiba. The methodology used was that of content analysis. A historical framework was created to identify the bases which generated the discourse in question, encompassing the institutionalization phase of urban planning in the 1960s and prior significant events that influenced it. The research revealed a close relationship between Curitiba's identity-building process and its urban planning ? the State's thought and action regarding urban spaces. The influence of both humanistic and rationalistic approaches to urban planning was identified on the generating bases of the discourse, as well as the influence of the political, economic, and social context which surrounded such discourse. By comprising a political project, urban planning discourse has as its product the city's 'summary image'. Therefore, this paper discusses the urban planning discourse in Curitiba, identifying its origins and distinguishing its supporting bases.
\end{abstract}

Keywords: Urban Planning Discourse. Humanistic and Rationalistic Influences in Urban Planning. Urban Planning Process. Curitiba. 


\section{Marcos antecedentes à instituciona- lização do processo de planejamento urbano}

A institucionalização do processo de planejamento urbano em Curitiba data dos anos 60, época em que os pressupostos da modernidade e da institucionalização embasaram as políticas públicas vigentes no país. Porém, importantes acontecimentos revelaram-se como seus marcos antecedentes e direta ou indiretamente a influenciaram, podendo até ser considerados como as suas origens.

Um primeiro marco antecedente, em meados da década de 1950, corresponde à emergência de um suporte técnico-institucional para o planejamento e o controle da urbanização, além da atualização do zoneamento proposto no Plano Agache, ${ }^{1}$ na gestão do então prefeito Ney Braga (1954-1958):² a criação do Departamento de Planejamento e Urbanismo da Prefeitura e a instituição da COPLAC - Comissão de Planejamento de Curitiba, órgão consultivo para intermediar a comunicação entre a sociedade e a prefeitura quanto a assuntos urbanísticos. ${ }^{3}$ Ressalta-se ainda nesta fase a assessoria

\footnotetext{
1. Plano de Urbanização de Curitiba (1943), também conhecido como Plano Agache, pois foi elaborado por Alfred Agache, urbanista francês. Conforme OBA (1999, p. 21), Alfred Hubert Donat Agache (1875-1959) estudou na Escola de Belas Artes de Paris e lecionou História da Arte no Colégio Livre de Ciências Sociais. Foi por muito tempo secretário-geral da Société Française dês Urbanistes (SFU). Foi 3o. colocado no concurso internacional de projeto para Camberra. Participou também de projeto urbanístico para a cidade de Chicago. Elaborou planos de urbanismo para Paris, Dunquerque, Poitiers, Dieppe, Tours, Orléans e Lisboa.
}

2. Ney Braga formou-se na Escola Militar do Realengo e na Escola do Estado Maior do Exército no Rio de Janeiro. Em 1952 iniciou na vida pública como titular da Chefatura de Polícia do Paraná. Em 1954 foi eleito prefeito de Curitiba (1954-1958). Em 1958, elegeu-se deputado federal e em 1960, governador do Paraná (1960-1965). Foi Ministro da Agricultura no governo do Mal. Castello Branco (1966-1968). Em 1968, elegeu-se senador. De 1974 a1978, ocupou o Ministério da Educação no governo do Gal. Ernesto Geisel. Foi novamente governador do Estado entre 1979 e 1982. Presidiu a Itaipu Binacional de 1985 a 1989. Veio a falecer em 2000

3. Esta comissão seria representada por entidades do comércio, indústria, cultura e associações técnicas, além de órgãos municipais e de vários engenheiros ligados à Universidade Federal do Paraná. A revisão do plano da cidade dar-se-ia a partir de um conjunto de planos setoriais, elaborados simultaneamente por diversas comissões técnicas. Cabe destacar nesse processo a participação do engenheiro Prestes Maia, trazido de São Paulo para prestar consultoria à COPLAC. Entre as suas contribuições à revisão do plano, pode-se ressaltar a importância da questão da preservação dos fundos de vale e da localização de uma zona industrial específica na bacia do Rio Barigüi. técnica do urbanista Prestes Maia ${ }^{4}$ à comissão na fase de revisão do plano.

Um segundo marco antecedente corresponde à criação do Curso de Arquitetura e Urbanismo da Universidade Federal do Paraná - UFPR -, em 1961. Do estreito vínculo existente entre a universidade e os setores públicos municipal e estadual, deriva a linha filosófica do planejamento urbano que se institucionalizaria ainda nesta década. As ideias de cidade e de planejamento urbano disseminadas pelas primeiras turmas do curso de arquitetura permeariam toda a concepção de um arcabouço técnico-institucional de planejamento urbano, uma vez que os primeiros arquitetos aqui formados tanto participariam dos quadros técnicos dos órgãos ligados às atividades de planejamento e de gestão urbana como também viriam a ocupar cargos político-administrativos nas três esferas de governo - municipal, estadual e federal.

O terceiro marco antecedente aqui eleito diz respeito ao processo de planejamento estadual instaurado na gestão de Ney Braga - então governador do Paraná (1961-1964) - podendo-se ressaltar a criação da Companhia de Desenvolvimento do Paraná - CODEPAR ${ }^{5}$ - e a formulação do Plano de Desenvolvimento do Paraná, ambos em 1963. Esse plano foi elaborado pela Sociedade de Análises Gráficas e Mecanográficas Aplicadas a Complexos Sociais - SAGMACS -, coordenada pelo Pe. Lebret, ${ }^{6}$ um dos fundadores da Escola de Economia e Humanismo na França.

\section{Bases geradoras do discurso do plane- jamento urbano: políticas, filosóficas e técnicas}

Pretende-se, agora, evidenciar a natureza do discurso oficial do planejamento urbano em Curitiba institucionalizado na gestão municipal

4. Francisco Prestes Maia - engenheiro civil e urbanista; em 1930, elaborou um Plano de Avenidas para São Paulo; quando prefeito da cidade de São Paulo na gestão 1938-1945, executa parte significativa do alargamento e da abertura de avenidas preparando a cidade para o desenvolvimento econômico das décadas seguintes: foi uma fase de intensas transformações urbanas. Prestes Maia foi prefeito em uma segunda gestão, de 1961 a 1965 (LEME, 1996, p. 254).

5.Empresa de economia mista, a CODEPAR tinha por competências o planejamento e o gerenciamento do Fundo de Desenvolvimento Estadual - FDE.

6.Pe. Joseph Louis Lebret, francês, era padre dominicano com ampla formação profissional: economista, demógrafo e sociólogo. 
de Ivo Arzua Pereira, ${ }^{7}$ a partir da elaboração do Plano Preliminar de Urbanismo (1965) - plano este responsável pela criação do Instituto de Pesquisa e Planejamento Urbano de Curitiba IPPUC -, durante a realização do Seminário "Curitiba de Amanhã" (1965) e que deu origem à Lei do Plano Diretor (1966).

O discurso do planejamento urbano é aqui compreendido como a síntese resultante da inter-relação entre as bases políticas, filosóficas e técnicas que o geraram. Porém, com a finalidade de organizar a construção do pensamento, uma consideração de ordem metodológica deve ser feita: as análises e interpretações a seguir possuem "ênfases" políticas ou filosóficas ou técnicas.

O período de aproximadamente doze anos, compreendido entre as gestões municipais de Ney Braga ${ }^{8}$ e Ivo Arzua Pereira (1954-1966) correspondeu à etapa de gestação ou de concepção do discurso do planejamento urbano em Curitiba.

Da época da criação do Departamento de Urbanismo da Prefeitura, devem ser ressaltadas como influências às bases do discurso:

- o despertar para a concepção do planejamento urbano como um processo, respaldada pela dinâmica da cidade em crescimento e pela iniciativa de atualizar o plano da cidade;

- a criação de órgãos responsáveis pelo planejamento e pela gestão urbana - o próprio Departamento de Urbanismo e a Comissão de Planejamento de Curitiba - COPLAC;

- a necessidade da formação de uma equipe técnica responsável pelas atividades de planejamento e gestão da cidade.

7. Ivo Arzua Pereira - engenheiro civil (UFPR 1948) e professor do Curso de Engenharia da UFPR, foi prefeito de Curitiba na gestão 1962-1966 pelo Partido Democrático Cristão - PDC - e ministro da Agricultura no governo do Gal. Artur da Costa e Silva (1967-1969).

8. Ney Braga entrou para o Partido Democrático Cristão - PDC - em 1958, ao final de seu mandato como prefeito de Curitiba. A democracia de inspiração cristã era tida como um caminho alternativo entre o capitalismo liberal e o sociocomunismo. Tinha como princípios filosóficos o humanismo, a solidariedade e o bem comum. Segundo Ribeiro e Cardoso (1994, p. 86), com a vinda de Pe. Lebret para o Brasil em 1947, o humanismo lebretiano teve ampla repercussão nos círculos católicos progressistas que tentavam articular um movimento pela "democracia cristã" nos anos 50. Por este motivo, o Partido Democrático Cristão compartilhava dos princípios lebretianos do humanismo, que ressaltavam o planejamento como um instrumento privilegiado de intervenção para o desenvolvimento social.
Com relação à criação do Curso de Arquitetura e Urbanismo da UFPR, podem ser destacadas como influências:

- a ideia do planejamento urbano como atividade processual e de caráter interdisciplinar;

- o princípio da racionalidade do planejamento urbano aplicado ao desenvolvimento, para suprir as necessidades de um homem universal;

- a ideia da imagem da cidade planejada associada a um discurso de modernidade;

- a valorização de profissionais habilitados para o exercício das atividades de planejamento e gestão urbana.

Como conseqüências da criação da CODEPAR e do Plano de Desenvolvimento do Paraná, poderiam ser evidenciadas:

- a importância de uma imagem da cidade associada à "capital de um estado que busca o progresso e o desenvolvimento";

- o pensamento da corrente humanista quanto à remoção de obstáculos para a realização da promoção humana, e o seu rebatimento nas intervenções sobre o espaço urbano.

\section{Articulação entre os atores na transição do contexto político}

O Estado 9 e a universidade ${ }^{10}$ foram identificados como os principais atores que contribuíram para o desencadeamento do processo de planejamento urbano em Curitiba, e consequentemente para a definição das bases do seu discurso. Com a intenção de decodificar as relações que sustentaram a construção e a legitimação do discurso, cabe agora identificar de que forma se articularam esses atores.

Em um primeiro momento, constata-se que o princípio filosófico do desenvolvimento econômico alavancado pela industrialização era, no período estudado - décadas de 1950 e 1960 -, comum às três esferas governamentais:

- o discurso vigente no país era o de promover o desenvolvimento econômico a partir da

9. O Estado aqui compreendido pelos níveis de governo municipal, estadual e federal.

10. A Universidade Federal do Paraná, aqui compreendida pelos cursos de Arquitetura e Urbanismo e de Engenharia. 
industrialização em substituição às importações e, para isso, era necessário integrar o território para formar um mercado nacional;

- ao mesmo tempo, no estado do Paraná, o discurso versava sobre a necessidade de integração de espaços econômicos distintos no território estadual - a capital e a região do norte cafeeiro - para dinamizar o escoamento da produção agrícola e propiciar a industrialização;

- em Curitiba, o discurso versava sobre a redefinição do perfil econômico da cidade por meio da implantação de um distrito industrial, através de ações de reordenamento territorial.

Paralelamente, identifica-se que as três esferas de governo partilhavam de uma mesma linha política quanto à condução desse processo de promoção do desenvolvimento, alicerçado na atividade do planejamento. A figura do plano representava a busca de uma nova identidade através da (re)construção das imagens do país, do Paraná e de Curitiba, associadas ao desenvolvimentismo:

- o Plano de Metas (Governo JK: 1955-1960): - país buscava alargar a sua base produtiva para além da agricultura - e assim construir uma nova imagem, sintetizada na nova capital do país, Brasília, o ícone da modernidade. Esta imagem, associada à urbanização, à infraestrutura, ao automóvel, à produção industrial, seria financiada pelos excedentes da produção de café;

- o Plano de Desenvolvimento do Paraná (Governo Ney Braga: 1961-1965): o Paraná um estado predominantemente agrícola - almejava construir uma nova imagem a partir da remodelação de seu perfil produtivo: a industrialização associada à uma nova imagem de sua capital, Curitiba, também a partir do excedente gerado pela economia cafeeira;

- o Plano Diretor de Curitiba (Governo de Ivo Arzua Pereira: 1962-1966): identificado com os propósitos do planejamento, o prefeito recém-eleito havia feito do reexame do Plano Agache a sua principal plataforma de campanha. Curitiba, a exemplo de Brasília, ansiava por uma nova imagem vinculada à modernidade, ancorada na infraestruturação urbana, no crescimento e no desenvolvimento, em um estilo de vida mais condizente com a sua condição de "capital".

Por fim, as três esferas governamentais consolidaram a institucionalização do processo de planejamento urbano e regional através da criação de órgãos específicos:

- o SERFHAU (1964) - Serviço Federal de Habitação e Urbanismo -, órgão criado para elaborar e coordenar a política nacional de planejamento local integrado, em articulação com os Ministérios do Planejamento e de Coordenação dos Organismos Regionais. Teria também de prestar assessoria técnica ao Banco Nacional de Habitação $(B N H)$ para a implantação da mencionada política, contribuindo para a integração do desenvolvimento regional e nacional;

- a CODEPAR (1962) - Companhia de Desenvolvimento do Estado do Paraná -, entidade criada para elaborar e implantar um novo modelo de desenvolvimento para o Estado do Paraná, objetivava financiar a infraestrutura básica para a dinamização do escoamento da produção agrícola e para a industrialização regional;

- o IPPUC (1965) - Instituto de Pesquisa e Planejamento Urbano de Curitiba -, órgão criado para detalhar e implantar o Plano Diretor - que incluía a criação de uma área industrial (futura CIC - Cidade Industrial de Curitiba) - e para gerenciar o processo de planejamento urbano.

\section{O discurso da cidade planejada: influ- ências humanista e racionalista}

O final dos anos 50, início dos 60, corresponde à fase de influência da corrente de pensamento de Pe. Lebret - Economia e Humanismo - sobre a construção do discurso do planejamento urbano em Curitiba. Como os postulados humanistas vinham ao encontro dos princípios da Democracia Cristã, foi notadamente marcante a sua internalização pelos democratas cristãos no Paraná. Com expressiva representatividade política no partido, Ney Braga, que estava à frente do governo estadual, foi um dos seus principais propagadores. Ivo Arzua Pereira, então prefeito de Curitiba e integrante do PDC, também comungava desses princípios. Somado a isso, grande parte dos quadros técnicos ligados ao planejamento havia estudado com Lebret, o que concorreu para a geração de um discurso de base humanista tanto no Paraná como em Curitiba.

Pode-se dizer, portanto, que o projeto de construção da identidade da cidade de Curitiba associada ao planejamento urbano foi legitimado, em sua fase inicial de institucionalização, sob 
um contexto político democrático e por meio de uma abordagem humanista. Porém, com o advento da revolução de 64 e a imposição do novo regime político, deu-se uma ruptura nesse processo pela mudança de postura do Estado brasileiro diante das políticas públicas. Tal fato teve ampla repercussão sobre a consolidação das bases do discurso do planejamento urbano nesse momento: a transição do discurso de ênfase humanista para racionalista, que se caracteriza pela tecnificação dos problemas urbanos e, portanto, por sua "despolitização".11

Nessa transição, cabe ressaltar a formação de um grupo coeso em torno da concepção do planejamento urbano como atividade racional e processual - ideia compartilhada pelos seus principais atores: a universidade e o Estado.

O Curso de Arquitetura e Urbanismo da UFPR exerceu influência direta na geração do discurso do planejamento urbano vinculado à construção da nova identidade da capital - condizente com "um Paraná a caminho do desenvolvimento industrial". Nesse contexto, a profissão do arquiteto e a figura do técnico obtiveram valorização e reconhecimento sem precedentes, em função do papel que desempenhariam como agentes da "transformação da imagem" da cidade e, portanto, da sua identidade.

A associação entre o poder político e o saber tecnicista ${ }^{12}$ que se deu a partir da articulação entre o Estado - em nível local - e a universidade veio legitimar a manutenção do padrão tecnicista já em curso - sustentado pela tradição de sucessivas gestões de prefeitos com formação em engenharia. Isto decorre da introdução do enfoque racionalista do planejamento urbano por influência do recém-criado Curso de Arquitetura e Urbanismo da UFPR, ${ }^{13}$ e vem a se cristalizar tanto na figura do Plano Preliminar de Urbanismo como na criação do IPPUC.

Nesse momento, faz-se importante ressaltar duas influências de concepção da universidade moderna no Brasil: a humboltiana, na criação da Universidade de São Paulo, e a napoleônica, na Universidade do Rio de Janeiro. Para Neves (2009), as universidades napoleônica e

11.Segundo Ribeiro e Cardoso (1994, p. 860).

12. O paradigma tecnicista caracterizou-se pelo uso da técnica por sua dimensão técnica e não por sua dimensão social.

13. Cabe ressaltar que tanto o Curso de Arquitetura e Urbanismo quanto o Plano Preliminar foram diretamente influenciados pela escola paulista de Arquitetura e Urbanismo. humboltiana caracterizaram-se a partir de princípios bastante distintos, apesar da sua contemporaneidade. A concepção francesa data do início do século XIX, época em que Napoleão Bonaparte controlava o Estado Imperial Francês. "Esta universidade teria sido concebida com o intuito de atender aos interesses de Napoleão que visava à construção da nação e a conservação da ordem pós-revolucionária" (apud NEVES, 2009, p. 26). Sendo assim, a universidade napoleônica seria uma instituição pública a serviço do poder do Estado, com a função de manter a ordem social pela difusão de uma doutrina comum. Nesse contexto, Drezze e Dabelle fazem uma crítica à atuação dos professores, que eram praticamente "guardas-civis intelectuais" a serviço do Imperador, ministrando um ensino acrítico e estritamente profissional (apud NEVES, 2009, p. 27). Constituída a partir de um conglomerado de faculdades voltada à formação profissional e com um arranjo institucional calcado no poder exacerbado do professor catedrático, a universidade napoleônica foi conduzida à fragmentação intrauniversitária. A partir do isolamento de suas unidades em "feudos acadêmicos", os princípios da universalidade e da uniformidade passaram a ser questionados. Ainda segundo estes autores, a concepção da universidade napoleônica perdurou na França até o final da década de sessenta.

Já a concepção de universidade humboltiana foi a que delineou a universidade moderna alemã. Com origens nas formulações kantianas, a Universidade de Berlim foi fundada por Humbolt tendo como pressuposto a dissociação entre poder e saber (NEVES, 2009, p. 20). O poder seria exercido pelos letrados ou homens de negócios, e seriam formados pelas faculdades superiores de Teologia, de Direito e de Medicina. $\mathrm{O}$ domínio do saber seria administrado pela faculdade inferior, e portanto estaria protegido da ingerência dos homens de negócios. Sendo assim, a comunicação desse saber pressupunha a necessidade de uma linguagem puramente teórica, movida unicamente pelo interesse da verdade (NEVES, 2009, p. 21). Para isso, não deveria ser popularizada e nem publicada ou divulgada.

Para Drezze e Dabelle, a universidade moderna alemã é regida por dois princípios estruturantes: a unidade do saber e a unidade da pesquisa e do ensino. A universidade não poderia seguir na busca pela verdade se não reconhecesse a pesquisa científica como tarefa fundamental, assentada sobre as noções de unidade e totalidade.

Apesar da influência da FAUUSP, a de ser uma universidade de concepção humboltiana - como 
referência curricular - o Curso de Arquitetura na UFPR nasceu dentro do Curso de Engenharia Civil, num momento político convergente em escala nacional, estadual e municipal - onde se constatou o alinhamento político entre Estado e universidade. Esse alinhamento é facilmente evidenciado pela sucessão de vários prefeitos engenheiros desde a primeira metade do século $X X$. Sendo assim, mesmo tendo uma matriz humboltiana, o Curso de Arquitetura da UFPR se constituiu a partir de princípios da universidade napoleônica, haja vista que está locado no Setor de Tecnologia da UFPR, ao passo que o da USP está vinculado às Ciências Humanas.

Da influência humboltiana advém o legado da visão do planejamento urbano como um processo, o que condicionou a criação do Instituto de Pesquisa e Planejamento Urbano de Curitiba IPPUC -, um órgão gestor do plano diretor em todas as suas etapas. Como decorrência, a inovadora ação de gestão urbana foi estendida ao país: seu reconhecimento pelo governo militar possibilitou a disseminação da experiência metodológica de Curitiba para todo o país, por meio da política nacional de planejamento.

A experiência de planejamento urbano de Curitiba foi legitimada desde o princípio pelas elites dominantes - técnica e econômica - e por toda uma população ávida de identidade. Sua legitimação pelo regime ditatorial teria sido favorecida em função das ligações do governador Ney Braga com a cúpula militar e posteriormente fortalecida, quando o SERFHAU - entidade responsável pela elaboração e coordenação da política nacional de planejamento local integrado -, dois anos depois da elaboração do Plano Preliminar de Urbanismo, contratou Jorge Wilheim para desenvolver um estudo sobre metodologia para elaboração de planos diretores, com o objetivo de ampliar a experiência bem-sucedida de Curitiba a todo o país. ${ }^{14}$

\section{Referências}

AUGUSTO, M. H. O. Intervencionismo estatal e ideologia desenvolvimentista: estudo sobre CODEPAR (Companhia de Desenvolvimento Econômico do Paraná). São Paulo: Símbolo, 1978.

BENEVIDES, M. V. de M. O governo Kubitschek: desenvolvimento econômico e estabilidade política - 1956-1961. 2. ed. Rio de Janeiro: Paz e Terra, 1976.

14. Jorge Wilheim, em depoimento à Memória da Curitiba Urbana. IPPUC (1990), Depoimentos 5, p. 35.
SÁ JR., A. F. de. Ney Braga: tradição e mudança na vida política. Curitiba: Ed. do Autor, 1996.

CURITIBA. Prefeitura Municipal. Plano de Urbanização de Curitiba: Plano Agache. Curitiba: Boletim PMC, 1943.

CURITIBA. Prefeitura Municipal. Documento Roteiro da Cidade: do bonde de mula ao ônibus expresso. Curitiba, 1975.

CURITIBA. Prefeitura Municipal. 25 anos CIC: Companhia de Desenvolvimento de Curitiba. Curitiba: CIC, 2000.

FORTE NETTO, Luiz. Palestra proferida na Câmara Municipal de Curitiba. In: SEMINÁRIO PLANO DIRETOR: UMA ABORDAGEM METROPOLITANA, 1., 1997, Curitiba. Anais... Curitiba, 1997.

Entrevista concedida à arquiteta Silviane Muller. Curitiba, mar. 2001.

GORDON, L. Um olhar americano. Entrevista concedida a Guilherme Evelin. Disponível em: http://epoca.globo.com/edic/ed25122000/index. htm>.

HABERT, N. A década de 70: apogeu e crise da ditadura militar. 3. ed. São Paulo: Ática, 1996.

IPPUC. IPPUC, 20 anos planejando Curitiba com você. (Publ. Comemorativa). Curitiba, 1985.

Memória da Curitiba Urbana: Depoimentos 1. Curitiba, nov. 1989. (Ivo Arzua Pereira).

Memória da Curitiba Urbana: Depoimentos 3. Curitiba, maio 1990. (F. Rischbieter, L. Dunin; N. Klüppel, A. Acho; C. Taniguchi).

Memória da Curitiba Urbana: Depoimentos 5. Curitiba, dez. 1990. (N. Braga; K. Rischbiete; J. Wilheim; S. Raiz e outros).

Memória da Curitiba Urbana: Depoimentos 7. Curitiba, set. 1991. (E. Brandão; T. Atherino; A . Fernandes; L. Forte Netto; G. Monteiro; M. Fernandes; J. Valduga; A. Carneiro; A. Willer; O . Akel; Z. Passos; M. Malucelli e outros).

Curitiba em fotos e fatos: 1535-1999. Curitiba: IPPUC, 1999. 
LEBRET, L. J. O drama do século XX: miséria, subdesenvolvimento, inconsciência, esperança. São Paulo: Duas Cidades, 1966.

LEITÃO, S. R. O discurso do planejamento urbano em Curitiba: um enigma entre a prática $e$ a cidade real. 2002. Dissertação (Mestrado em Estruturas Ambientais Urbanas) - FAUUSP, São Paulo, 2002.

LEITE, T. Opção para um Brasil viável: economia social de mercado, decisão racional e social, social-democracia cristã. Fortaleza [19--].

LEME, M. C. da S. A formação do urbanismo como disciplina e profissão: São Paulo na primeira metade do século XX. In: RIBEIRO, L. C. Q.; PECHMAN, R. M. (Org.). Cidade, povo e nação: gênese do urbanismo moderno. Rio de Janeiro: Civilização Brasileira, 1996. p. 227-244.

LOURENÇO, G. M. Retaguarda institucional das transformações econômicas no Paraná. Análise Conjuntural, v. 22, n.11-12, p. 2-9, nov.-dez. 2000.

MAZZA, L. G. A Sorbonne do meu bairro. In: Memória da Curitiba urbana: Depoimentos 1. Curitiba: IPPUC, 1989. p. 21-24.

NEVES, R. R. Universidade Federal do Rio de Janeiro: território e integração. 2009. Dissertação (Mestrado em Planejamento Urbano e Regional) - Universidade do Rio de Janeiro, Rio de Janeiro, 2009.

OBA, L. T. Marcos urbanos e a construção da cidade: a identidade de Curitiba. São Paulo, 1999. Tese (Doutorado em Arquitetura e Urbanismo) - Faculdade de Arquitetura e Urbanismo, Universidade de São Paulo, 1999.

OLIVEIRA, D. de. Curitiba e o mito da cidade modelo. Curitiba: Ed. da UFPR, 2000.

PAES, M. H. S. A década de 60: rebeldia, contestação e repressão política. 4. ed. São Paulo: Ática, 1997.

PEREIRA, I. A. Palestra proferida na Câmara Municipal de Curitiba. In: SEMINÁRIO PLANO DIRETOR DE CURITIBA: UMA ABORDAGEM METROPOLITANA, 1., 1997, Curitiba. Disponível em: <http://www.samek.com.br/samek/plano/ bdd/1.htm>. Acesso em: 9. abr. 2001.

PEREIRA, M. da S. Pensando a metrópole moderna: os planos de Agache e Le Corbusier para o Rio de Janeiro. In: RIBEIRO, L. C. Q.; PECHMAN, R. M. (Org.). Cidade, povo e nação: gênese do urbanismo moderno. Rio de Janeiro: Civilização Brasileira, 1996. p. 363-376.

CURITIBA. Prefeitura Municipal. Plano de Urbanização de Curitiba: Plano Agache. Curitiba: Boletim PMC, 1943.

CURITIBA. Prefeitura Municipal. Documento Roteiro da Cidade: do bonde de mula ao ônibus expresso. Curitiba, 1975.

PUPPI, I. C. Fatos e reminiscências da faculdade. Curitiba: Fundação da Universidade Federal do Paraná, 1986.

RIBEIRO, L. C. Q.; CARDOSO, A. L. Planejamento urbano no Brasil: paradigmas e experiências. Espaço e Debates, São Paulo, n. 37, 1994.

RODRIGUES, M. A década de 80 - Brasil: quando a multidão voltou às praças. 2. ed. São Paulo: Ática, 1994.

A década de 50: populismo e metas desenvolvimentistas no Brasil. 3. ed. São Paulo: Ática, 1996.

SANTOS, M. A urbanização brasileira. 3. ed. São Paulo: Hucitec, 1994. (Estudos Urbanos, 5).

WILHEIM, J. Palestra proferida na Câmara Municipal de Curitiba. In: SEMINÁRIO PLANO DIRETOR DE CURITIBA: UMA ABORDAGEM METROPOLITANA, 1., 1997, Curitiba. Disponível em: <http://www.samek.com.br/samek/plano/ bdd/1.htm>. Acesso em: 9 abr. 2001. 
